\title{
Removal of Carcinogenic Hexavalent Chromium by Reduction with Iron in Presence of Accelerator Non Toxic Organic Compounds (Chalcone)
}

\author{
Hanaa H. Abdel Rahman, Amira H.E. Moustafa*, Mohamed A. Z. Mostafa, \\ ElsaiedM. Abdel Wahed \\ Chemistry Department, Faculty of Science, Alexandria University, Alexandria, Egypt \\ hhabdelrahman10@yahoo.ca \\ amirahossameldin79@yahoo.com \\ mabdelzaher15@yahoo.com
}

\begin{abstract}
The focus of this work is on $\mathrm{Cr}$, which has two predominant oxidation states of the atmosphere: +3 , which is an essential nutrient in low doses, and +6 , which is highly toxic and carcinogenic. We found that, the reduction of $\mathrm{Cr}^{6+}$ to $\mathrm{Cr}^{3+}$ was first order reaction and the rate controlling step is the diffusion of $\left(\mathrm{Cr}^{6+}\right)$ from bulk to iron surface. Toxicity reduction method includes studding of 1-aryl-3-(1-phenylpyrazolo [3,4-b] quinoxalin-3-yl) -2-propenones derivatives or chalcone derivatives concentration, temperatures and rotation speeds effect, which exhibit a strong dependence and supported that the process is diffusion controlled. Thermodynamic parameter $\Delta \mathrm{G}^{*}, \Delta \mathrm{H}^{*}$ and $\Delta \mathrm{S}^{*}$ are given. Mass transfer study of the process was correlated by the equation: $\mathrm{Sh}=0.53 \mathrm{Sc}^{0.33} \mathrm{Re}^{0.38}$. The order of acceleration was confirmed by quantum calculations.
\end{abstract}

Keywords: Hexavalent chromium; Pyrazoloquinoxaline derivatives; Diffusion controlled; Temperature, Quantum calculations.

\section{Council for Innovative Research}

Peer Review Research Publishing System

Journal: Journal of Advances in Chemistry

Vol. 11, No. 4

editorjaconline@gmail.com

www.cirjac.com 


\section{INTRODUCTION}

Industrial activities have an important role in environmental pollution, especially those that use chromium (Cr) in the production process. For the global industrial age, the cumulative $\mathrm{Cr}$ production has increased significantly since the 1950 s, and has been estimated at $105.4 \mathrm{Mt}$ in 2000 . The presence of heavy metals in aquatic environments is known to cause severe damage to aquatic life beside the fact that these metals kill microorganisms during biological treatment of waste water with a consequent delay in the process of water purification. ${ }^{1}$

Throughout the last century, heavy metal contamination of aqueous environment has earned much attention due to the significant potential health impact on the public. Due to the fact that chromium is one of the most toxic metals that have been released into the environment, it has become a serious health concern. Chromium is commonly used in industrial applications, such as: tanning process, electroplating, pigmentation, catalyst for corrosion inhibitors, metal finishing, nuclear power plant, textile industries and wood preservatives. ${ }^{2,3}$

Chromium exists in two common oxidation states as $\mathrm{Cr}$ (III) and $\mathrm{Cr}(\mathrm{VI})$. The hexavalent form is 500 times more toxic than the trivalent. It is toxic to microorganism plants, animals and humans. Human toxicity includes lung cancer, as well as kidney, liver and gastric damage. ${ }^{4,5}$ Due to severe toxicity of $\mathrm{Cr}(\mathrm{VI})$, the USEPA (US environmental protection agency) has set the maximum contaminate level for $\mathrm{Cr}(\mathrm{VI})$ in domestic water supplies to be 0.05 ppm. ${ }^{6}$ Trivalent forms is an essential nutrient, but hexavalent form is toxic, carcinogenic and mutagenic in nature. It is highly mobile in soil and aquatic system and also is a strong oxidant capable of being assimilated by the skin. ${ }^{7,8}$ Therefore, the reduction of $\mathrm{Cr}(\mathrm{VI})$ to the $\mathrm{Cr}$ (III) is of environmental interest. Much work has been focused on the cleanup of $\mathrm{Cr}$ (VI) -contaminated waters by various reducing agents. Chemical reduction is known to remove hexavalent chromium rapidly and effectively, reduction using iron metal appears to be one of the most promising technologies. ${ }^{9}$ The effect of iron metal type and $\mathrm{pH}$ value of a rate of hexavalent chromium reduction by iron was evaluated. ${ }^{10}$

In this paper, we describe the effect of pyrazoloquinoxaline derivatives, which attached to calcine moiety as a side chain on the reduced rate of $\mathrm{Cr}(\mathrm{VI})$ to $\mathrm{Cr}$ (III) on the iron sheet at different RPM $(100,200,500$ and $1000 \mathrm{RPM})$ and at different temperatures $\left(25,30,35\right.$ and $\left.40^{\circ} \mathrm{C}\right)$ in order to judge the role of those additives on reduction of $\mathrm{Cr}(\mathrm{VI})$ to $\mathrm{Cr}$ (III) and to correlate the thermodynamic parameters of activation. The chalcones derivatives were used because they are non toxic and have a biological effect. ${ }^{11}$ Physical properties of solution such as density, viscosity and diffusion coefficient are studied to obtain a dimensionless correlation. Quantum chemical parameters were calculated using semi-empirical AM1 and PM3 method to find a good correlation with experimental results.

\section{EXPERIMENTAL}

\subsection{Materials}

Annular grade $\mathrm{K}_{2} \mathrm{Cr}_{2} \mathrm{O}_{7}$ and $\mathrm{H}_{2} \mathrm{SO}_{4}(98 \%$ w/w), supplied by $\mathrm{BDH}$ Chemicals Ltd and distilled water was used in the preparation of solutions.

The organic additives selected in the present work are a series of 1-aryl-3-(1-phenylpyrazolo [3,4- $b]$ quinoxalin-3yl) -2-propenones derivatives listed below (Figure 1) (synthesized earlier by M. M. Abdel Zaher). ${ }^{12}$

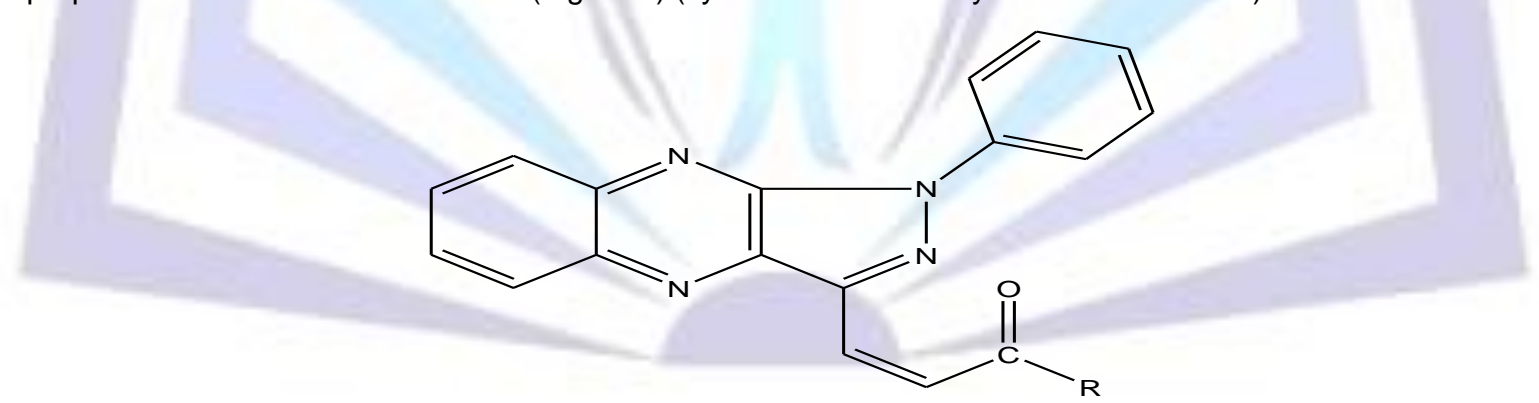

Figure 1. Chemical structureof chalcone.

\begin{tabular}{|c|l|l|}
\hline $\mathbf{2 a}$ & $\mathrm{R}=$ phenyl & 1-phenyl-3-(1-phenypyrazolo[3,4-b]quinoxalin-3-yl)-2- propenone \\
\hline $\mathbf{2 b}$ & $\mathrm{R}=p$-tolyl & 1-p-tolyl -3-(1-phenylpyrazolo [3,4-b] quinoxalin- 3-yl)-2- propenone \\
\hline $\mathbf{2 c}$ & $\mathrm{R}=p$-chloro phenyl & 1-(4-chlorophenyl)-3-(1-phenylpyrazolo[3,4- $b] q u i n o x a l i n-3-y l)-2-p r o p e n o n e$ \\
\hline $\mathbf{2 d}$ & $\mathrm{R}=p$-bromo phenyl & 1-(4-bromophenyl))-3-(1-phenylpyrazolo[3,4- $b] q u i n o x a l i n-3-y l)-2-p r o p e n o n e$ \\
\hline $\mathbf{2 e}$ & $\mathrm{R}=$ biphenyl & 1-(biphenyl)-3-(1-phenylpyrazolo[3,4- $b]$ quinoxalin-3-yl)-2- propenone \\
\hline
\end{tabular}




\subsection{Kinetic measurements}

Fresh solution of $\mathrm{K}_{2} \mathrm{Cr}_{2} \mathrm{O}_{7}(1000 \mathrm{ppm}), \mathrm{H}_{2} \mathrm{SO}_{4}\left(2 \mathrm{~mol} \mathrm{~L}^{-1}\right)$ and stock solutions of additives (2a-2e) were prepared, with concentrations $3.0 \times 10^{-7}, 3.0 \times 10^{-6}, 6.0 \times 10^{-6}, 1.2 \times 10^{-5}, 2.4 \times 10^{-5}$ and $3.0 \times 10^{-5} \mathrm{~mol} \mathrm{~L}^{-1}$ respectively.

The apparatus used consists of $500 \mathrm{~mL}$ glass beaker containing $500 \mathrm{~mL} \mathrm{~K}_{2} \mathrm{Cr}_{2} \mathrm{O}_{7}$ and $\mathrm{H}_{2} \mathrm{SO}_{4}$ solution with or without chalcones (2a-2e) in which iron sheet of length $7.5 \mathrm{~cm}$ and width $3.33 \mathrm{~cm}$ is immersed. The Thermal magnetic stirring has rpm $100,200,500,750$ and 1000 are employed. The determination of hexavalent chromium, Cr (VI) concentration was carried out at $365 \mathrm{~nm}$ using Unicam-9423-UV-E Spectrophotometer.

\subsection{Density and viscosity measurements}

The density was measured by using DA-300 Kyoto Electronics at $25,30,35$, and $40 \pm 1^{\circ} \mathrm{C}$. The viscosity was measured by using Koehler viscosity bathing (model K23400 Kinematic bath) at 25, 30, 35 and $40 \pm 1^{\circ} \mathrm{C}$.

\subsection{Theoretical method}

The molecular structures of the investigated pyrazoloquinoxaline derivatives were optimized initially using AM1 and PM3 semi-empirical chemical methods implemented in MOPAC 2009. The calculated quantum chemical parameters

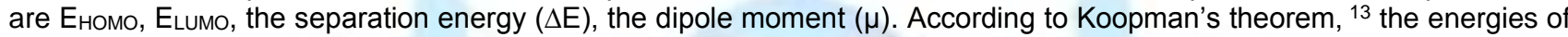
theHOMO and the LUMO orbital's of the accelerator molecule arerelated to the ionization potential, I, and the electron affinity, A,respectively, by the following relations:

$$
\begin{aligned}
& I=-E_{\text {Hомо }} \\
& A=-E_{\text {LUMO }}
\end{aligned}
$$

Absolute hardness, $\eta$, of the accelerator molecule is given by: ${ }^{14}$

$$
\eta=1 / 2(I-A)
$$

The softness is the inverse of the hardness:

$\sigma=1 / \eta$

\section{RESULTS AND DISCUSSION}

\subsection{Reaction kinetics}

In our work, oxidation-reduction reaction between hexavalent chromium ions $\mathrm{Cr}$ (VI) (toxic) and iron takes place to produce trivalent chromium ion $\mathrm{Cr}$ (III). The rate controlling step was found to be the diffusion of hexavalent chromium ion to iron surface. In this case, the change in the rate of $\mathrm{Cr}(\mathrm{VI})$ concentration in the solution is followed according to the equation (4):

$$
d C / d t=-k A C / V
$$

where $k$ is the mass transfer coefficient $\left(\mathrm{cm} \mathrm{sec}^{-1}\right), t$ is reaction time $(\mathrm{min}), C$ is the concentration at time $\mathrm{t}(\mathrm{mg}$ $\left.\mathrm{L}^{-1}\right), A$ is the exposed area of the iron sheet $\left(\mathrm{cm}^{2}\right)$ and $V \mathrm{IS}$ the volume of solution $\left(\mathrm{cm}^{3}\right)$; assuming that $\mathrm{Cr}(\mathrm{VI})$ concentration is negligible at an iron solution interface. Consequently, the rate of hexavalent chromium ion reduction is proportional to its concentration and the exposed iron area. The mechanism of the reaction seems to be electrochemical in nature i.e. it takes place through galvanic cell where Fe acts as the cell anode while the carbon content in the iron metal act as cathode:

$$
\begin{array}{lc}
\mathrm{Fe} / \mathrm{Fe}^{2+} / \mathrm{Cr}^{6+}, \mathrm{Cr}^{3+} & \text { (galvanic cell) } \\
\text { At anode: }(\mathrm{Fe}) & \mathrm{Fe} \rightarrow \mathrm{Fe}^{2+}+2 \mathrm{e}^{-} \\
\text {At cathode: (carbon) } & \mathrm{Cr}^{6+}+3 \mathrm{e} \rightarrow \mathrm{Cr}^{3+}
\end{array}
$$

From above the reaction:

$$
\mathrm{Cr}^{6+}+3 \mathrm{Fe}^{2+} \rightarrow 3 \mathrm{Fe}^{3+}+\mathrm{Cr}^{3+}
$$

The integrated form of the first order equation can be described as: 
Plot $\log C_{o} / C$ and time gives a straight line pass with origin, which indicates that the reaction is first order. This was verified by previous workers. ${ }^{15-18}$

\subsection{Factors affecting the reaction}

\subsubsection{Effect of the concentration of $\mathrm{Cr}(\mathrm{VI})$}

The rate of oxidation-reduction reaction between $\mathrm{Cr}(\mathrm{VI})$ ion and iron has been examined at different concentrations of $\mathrm{Cr}(\mathrm{VI})$ solution $(50,75,100,250$ and $500 \mathrm{ppm})$. Figure 2 shows the relation between log $\mathrm{C}_{0} / \mathrm{C}$ and time in the presence of different concentrations of $\mathrm{Cr}(\mathrm{VI})$, from which the mass transfer coefficient was calculated as giving in Table 1. It is clear from Table 1 that the values of mass transfer increase with increasing the concentration of $\mathrm{Cr}(\mathrm{VI})$ which is in agreement with the reported result. ${ }^{19}$

Table 1.The values of mass transfer coefficient for different concentrations of $\mathrm{Cr}^{6+}$ solution at $750 \mathrm{rpm}$ and $25^{\circ} \mathrm{C}$. (blank solution).

\begin{tabular}{|c|c|c|c|c|c|}
\hline Conc. $(\mathrm{ppm})$ & 50 & 75 & 100 & 250 & 500 \\
\hline $\mathrm{k} \times 10^{3}\left(\mathrm{~cm} \mathrm{sec}^{-1}\right)$ & 2.23 & 2.41 & 2.65 & 3.18 & 3.49 \\
\hline
\end{tabular}

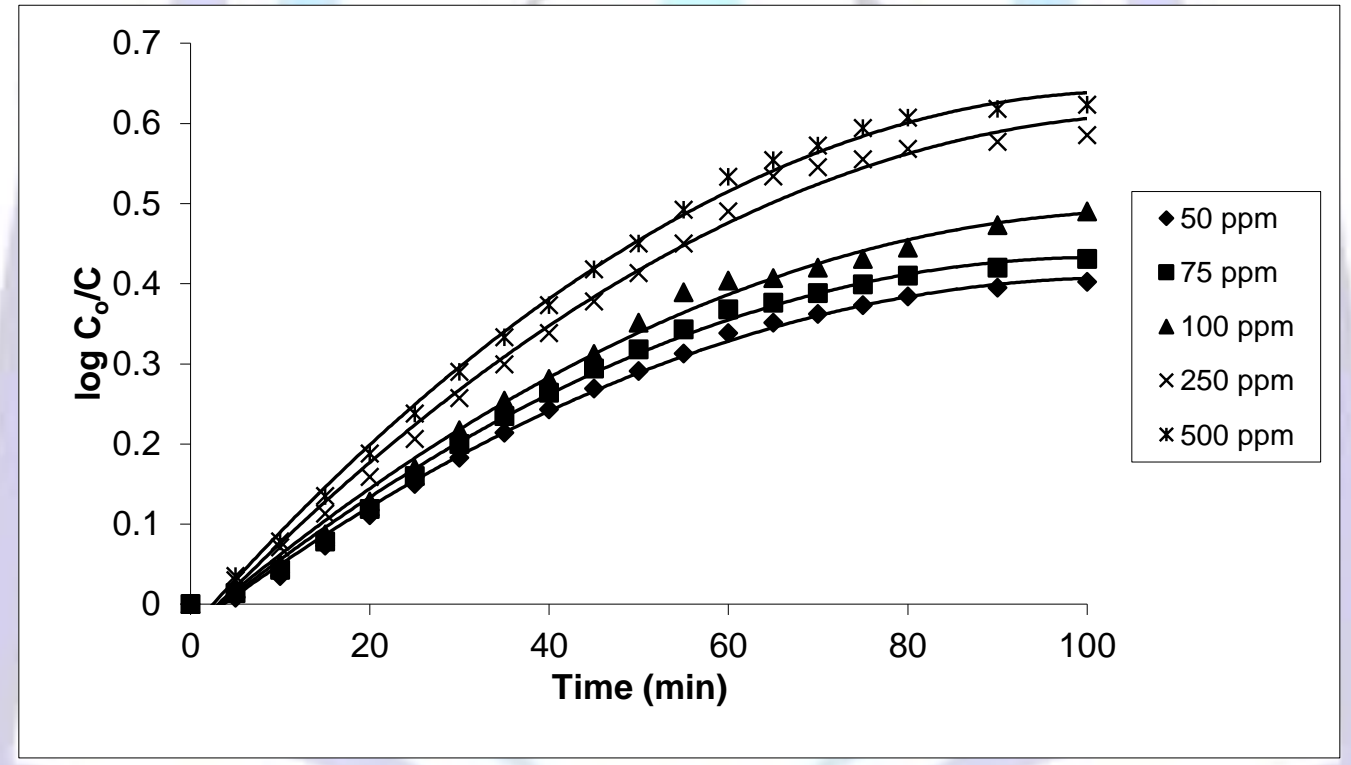

Figure 2. The relation between $\log \mathrm{C}_{0} / \mathrm{C}$ and time at different concentrations of blank $\mathrm{Cr}^{6+}$ at $25^{\circ} \mathrm{C}$ and $750 \mathrm{rpm}$.

\subsubsection{Effect of stirring on the reaction}

The reduction rate was measured at different rotations at $25^{\circ} \mathrm{C}$ for acidified hexavalent chromium ion solution as a blank solution as well as in the presence of chalcones, the rotation rate were $0,100,200,500,750$ and $1000 \mathrm{rpm}$. The effect of rotation speed on the mass transfer coefficient $(k)$ used to determine whether a reaction is diffusion or chemically controlled. If the mass transfer coefficient $(k)$ increases with increased stirring speed, then the reaction is diffusion controlled. If $k$ is independent on stirring speed, then the reaction is chemically controlled. The data shown in the Table 2 represents that the reaction is diffusion controlled. ${ }^{20,21}$

\subsubsection{Effect of diffusion coefficient on the mass transfer coefficients}

Table 3 gives the values of diffusion coefficients in absence and in the presence of chalcones (2a-2e). It is obvious that the presence of chalcones $(2 \mathrm{a}-2 \mathrm{e})$ increasing the diffusion coefficient $(D)$ of the solution containing hexavalent chromium $\mathrm{Cr}(\mathrm{VI})$ till to a certain concentration. This is due to decreasing in the interfacial viscosity in accordance with Stokes-Einstein equation (3), and increasing the mass transfer coefficient. ${ }^{1,21}$

$$
\eta D / T=\text { constant }
$$


Table 2. The values of mass transfer coefficient $\left(\mathrm{k} \times 10^{2} \mathrm{~cm} \mathrm{sec}^{-1}\right)$ for $100 \mathrm{ppm} \mathrm{Cr}^{6+}$ and different chalcones solution of concentration $\left(3.0 \times 10^{-7} \mathrm{~mol} \mathrm{~L}^{-1}\right)$ at different rotation speeds and $25^{\circ} \mathrm{C}$.

\begin{tabular}{|c|c|c|c|c|c|c|}
\hline \multirow{2}{*}{ Speed ( rpm) } & \multicolumn{7}{|c|}{$\mathrm{k} \times 10^{2} \mathrm{~cm} \mathrm{sec}^{-1}$} & $2 \mathrm{e}$ \\
\cline { 2 - 7 } & Blank & $2 \mathrm{a}$ & $2 \mathrm{~b}$ & $2 \mathrm{c}$ & $2 \mathrm{~d}$ & 1.23 \\
\hline 0 & 0.95 & 1.23 & 1.19 & 1.34 & 1.54 & 2.30 \\
\hline 100 & 1.18 & 2.34 & 2.26 & 3.00 & 3.23 & 2.80 \\
\hline 200 & 1.77 & 2.83 & 2.76 & 3.41 & 3.61 & 3.23 \\
\hline 500 & 2.03 & 3.30 & 3.23 & 3.72 & 3.95 & 4.03 \\
\hline 750 & 2.65 & 4.07 & 3.73 & 4.15 & 4.49 & 4.72 \\
\hline 1000 & 3.46 & 4.80 & 4.41 & 4.91 & 5.52 & 4.52 \\
\hline
\end{tabular}

where, $T$ is absolute temperature. Data represented in Table 3 also shows that the diffusion coefficient of the solution increases with increasing temperature. This is due to decreasing viscosity by increasing the temperature. On the other hand, increasing of $D$ leads to the increasing mass transfer coefficient which shown by Figure 3.

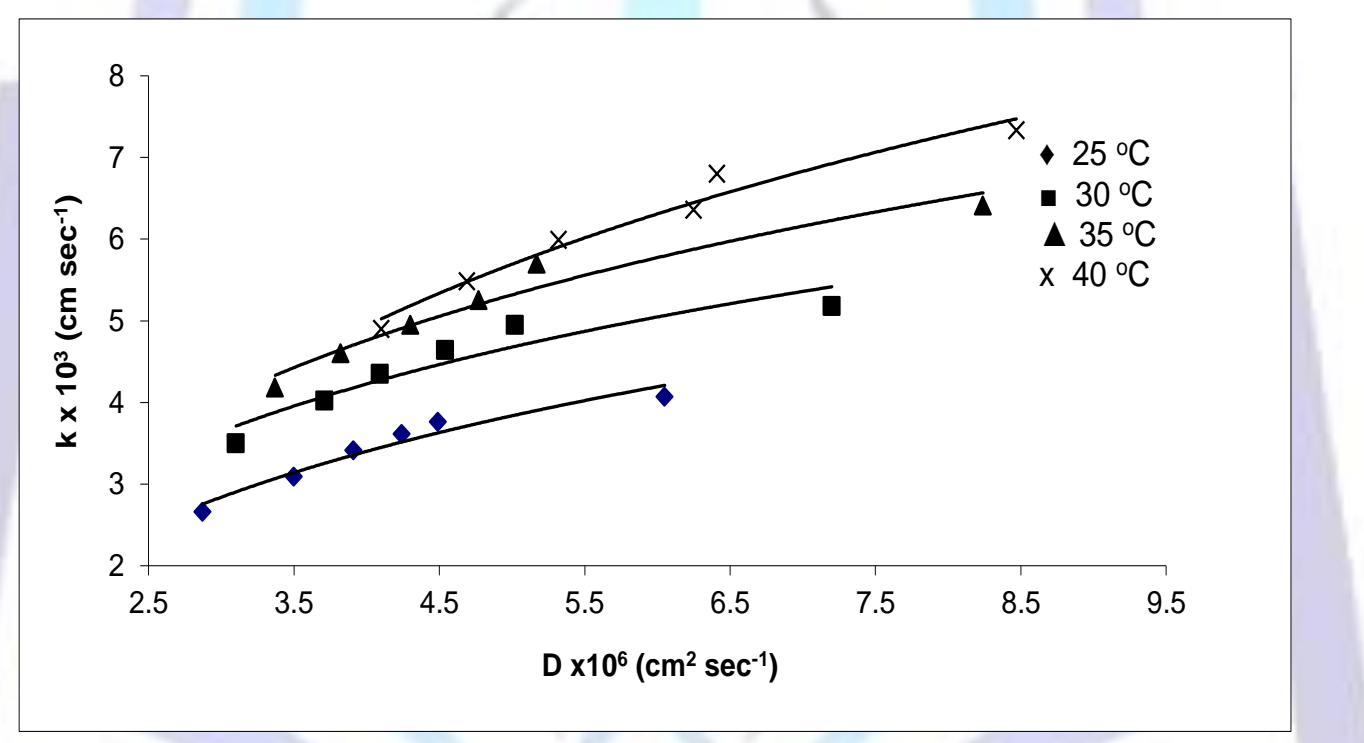

Figure 3.The relation between mass transfer coefficient and diffusion coefficient (D) for $100 \mathrm{ppm} \mathrm{Cr}^{6+}$ solution containing different concentrations of $2 \mathrm{a}$ at different temperatures and $750 \mathrm{rpm}$.

\subsubsection{Influence of temperature}

The rate of oxidation-reduction reaction of $\mathrm{Cr}(\mathrm{VI})$ was examined at different temperatures $\left(25,30,35\right.$ and $\left.40^{\circ} \mathrm{C}\right)$ for blank solution as well as in the presence of chalcones (2a-2e). Data presented in Table 4 indicates that, the reaction rate increases by increasing temperature. This refers to the $\mathrm{Cr}(\mathrm{VI})$ species may be activated due to gain kinetic energy and reduced by iron. ${ }^{22}$ The reaction rate can be regarded as an Arrhenius-type process. ${ }^{10}$

Arrhenius plot for oxidation-reduction reaction in the absence and presence of chalcone are given in Figure 4 (2a as an example) and the corresponding activation parameters $\left(E_{a}, \Delta H^{*}\right.$ and $\left.\Delta S^{*}\right)$ for oxidation-reduction reaction was estimated and listed in Tables 5,6 the change in the activation free energy $\left(\Delta \mathrm{G}^{*}\right)$ of the process can be calculated at $25^{\circ} \mathrm{C} .{ }^{23}$

The obtained $\Delta G^{*}$ values were also listed in Table 6 . According to the data recorded in Tables 5,6 the following discussion can be written:

- In diffusion controlled processes the activation energy is mostly below $10 \mathrm{kcal} \mathrm{mol}^{-1}$. Activation energies are ranged from 26.99 to33. $72 \mathrm{~kJ} \mathrm{~mol}^{-1}$ in the absence and presence of chalcones. This indicates that the reaction is controlled by diffusion processes. ${ }^{20,24,25}$

- The negative values of $\Delta \mathrm{S}^{*}$ pointed to a greater order produced during the process of activation. 
- The change in free energy of activation $\Delta G^{*}$ with the studied organic compound concentrations used is only small as shown in Table 6 and variation occur in the enthalpy of activation $\Delta \mathrm{H}^{*}$ and the entropy of activation $\Delta \mathrm{S}^{*}$ with the organic compound, where concentrations, in all cases $\Delta \mathrm{H}^{*}$ and $\Delta \mathrm{S}^{*}$ compensate each other to produce little change in $\Delta \mathrm{G}^{*}$.

- Isokinetic temperature represents the variation of $\Delta \mathrm{H}^{*}$ with $\Delta \mathrm{S}^{*}$, where slope represents the isokinetic temperature. Figure 5 shows that $\Delta \mathrm{H}^{*}$ varies linearly with $\Delta \mathrm{S}^{*}$ for all organic compounds used, and these plots lie on the same straight line, indicating a close similarity in the mechanism. ${ }^{23}$

Table 3.The values of diffusion coefficient (D) and kinematic viscosity (v)for $100 \mathrm{ppm} \mathrm{Cr}^{6+}$ solution in the presence of different concentrations of chalcones $(2 \mathrm{a}-2 \mathrm{e})$ at different temperatures and $750 \mathrm{rpm}$.

2a

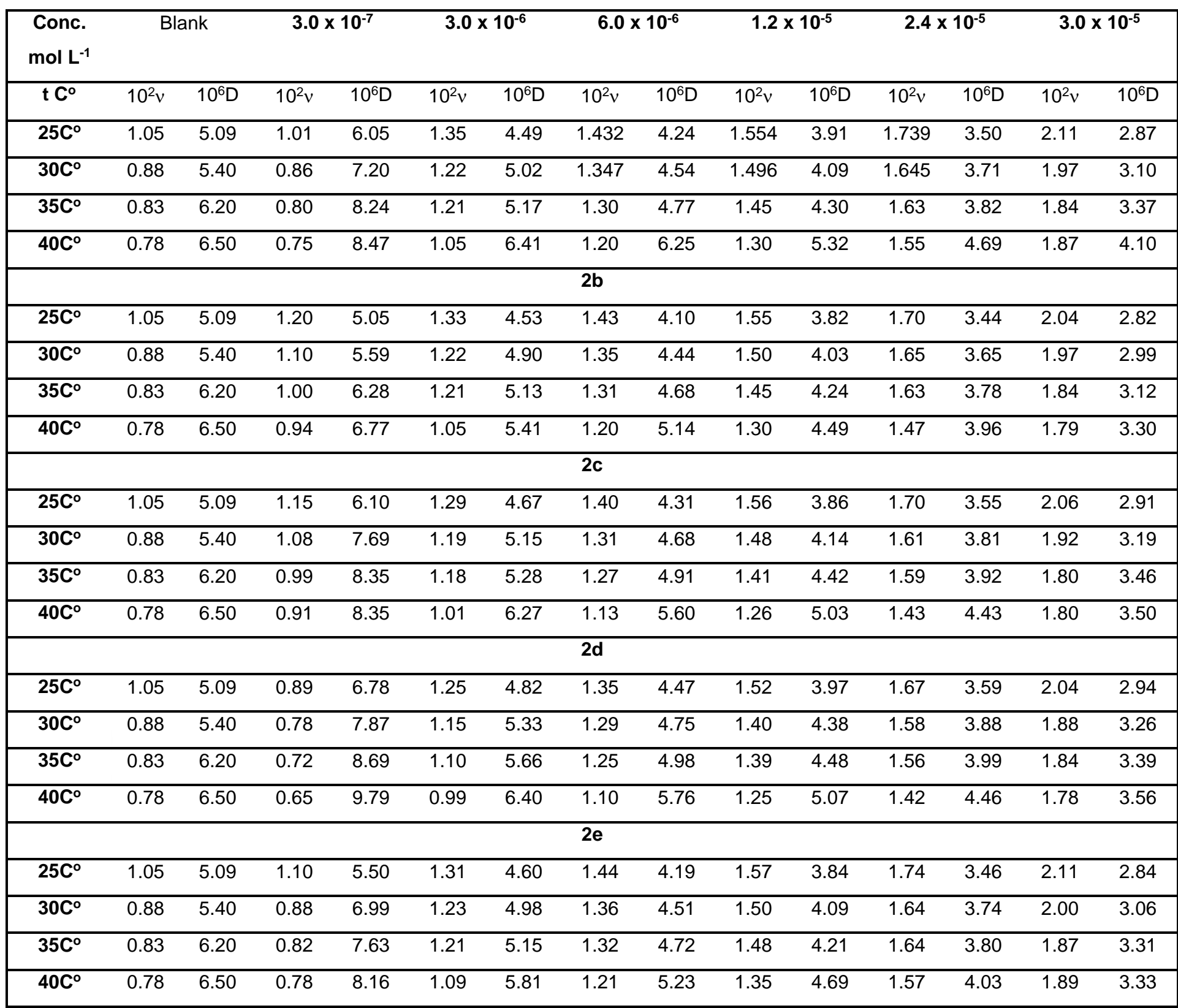




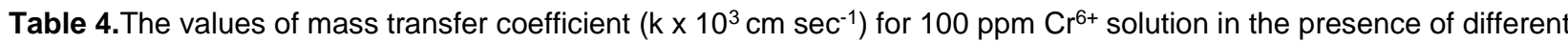
concentrations of chalcones (2a-2e) at different temperatures and $750 \mathrm{rpm}$.

\begin{tabular}{|c|c|c|c|c|c|c|c|}
\hline \multicolumn{8}{|c|}{$2 a$} \\
\hline $\mathrm{T}^{\circ} \mathrm{C}$ & Blank & $3.0 \times 10^{-7}$ & $3.0 \times 10^{-6}$ & $6.0 \times 10^{-6}$ & $1.2 \times 10^{-5}$ & $2.4 \times 10^{-5}$ & $3.0 \times 10^{-5}$ \\
\hline $25^{\circ} \mathrm{C}$ & 2.65 & 4.07 & 3.76 & 3.61 & 3.41 & 3.09 & 2.66 \\
\hline $30^{\circ} \mathrm{C}$ & 3.72 & 5.18 & 4.95 & 4.64 & 4.35 & 4.02 & 3.50 \\
\hline $35^{\circ} \mathrm{C}$ & 4.02 & 6.41 & 5.70 & 5.25 & 4.95 & 4.60 & 4.18 \\
\hline $40^{\circ} \mathrm{C}$ & 4.60 & 7.33 & 6.80 & 6.36 & 5.99 & 5.48 & 4.90 \\
\hline \multicolumn{8}{|c|}{$2 b$} \\
\hline $25^{\circ} \mathrm{C}$ & 2.65 & 3.73 & 3.53 & 3.36 & 3.15 & 2.99 & 2.65 \\
\hline $30^{\circ} \mathrm{C}$ & 3.72 & 4.85 & 4.58 & 4.34 & 4.00 & 3.73 & 3.12 \\
\hline $35^{\circ} \mathrm{C}$ & 4.02 & 6.11 & 5.32 & 4.91 & 4.91 & 4.10 & 3.84 \\
\hline $40^{\circ} \mathrm{C}$ & 4.60 & 7.12 & 6.58 & 6.11 & 5.77 & 5.36 & 4.75 \\
\hline \multicolumn{8}{|c|}{$2 c$} \\
\hline $25^{\circ} \mathrm{C}$ & 2.65 & 4.15 & 3.87 & 3.63 & 3.32 & 3.05 & 2.66 \\
\hline $30^{\circ} \mathrm{C}$ & 3.72 & 5.19 & 4.92 & 4.65 & 4.34 & 4.07 & 3.60 \\
\hline $35^{\circ} \mathrm{C}$ & 4.02 & 6.51 & 5.74 & 5.36 & 5.02 & 4.72 & 4.21 \\
\hline $40^{\circ} \mathrm{C}$ & 4.60 & 7.43 & 6.95 & 6.55 & 6.07 & 5.63 & 4.98 \\
\hline \multicolumn{8}{|c|}{$2 d$} \\
\hline $25^{\circ} \mathrm{C}$ & 2.65 & 4.49 & 3.93 & 3.67 & 3.43 & 3.15 & 2.71 \\
\hline $30^{\circ} \mathrm{C}$ & 3.72 & 5.39 & 4.98 & 4.72 & 4.48 & 4.07 & 3.67 \\
\hline $35^{\circ} \mathrm{C}$ & 4.02 & 6.62 & 6.07 & 5.57 & 5.22 & 4.86 & 4.17 \\
\hline $40^{\circ} \mathrm{C}$ & 4.60 & 7.51 & 7.16 & 6.79 & 6.20 & 5.70 & 5.26 \\
\hline \multicolumn{8}{|c|}{$2 e$} \\
\hline $25^{\circ} \mathrm{C}$ & 2.65 & 4.05 & 3.73 & 3.46 & 3.25 & 3.02 & 2.70 \\
\hline $30^{\circ} \mathrm{C}$ & 3.72 & 5.09 & 4.92 & 4.54 & 4.24 & 3.93 & 3.49 \\
\hline $35^{\circ} \mathrm{C}$ & 4.02 & 6.31 & 5.66 & 5.22 & 4.85 & 4.58 & 4.11 \\
\hline $40^{\circ} \mathrm{C}$ & 4.60 & 7.26 & 6.79 & 6.24 & 5.94 & 5.43 & 4.90 \\
\hline
\end{tabular}

Table 5.Values of activation energy $\left(\mathrm{E}_{\mathrm{a} \mathrm{kJ} \mathrm{mol}}{ }^{-1}\right)$ for $100 \mathrm{ppm} \mathrm{Cr}^{6+}$ solution with and without chalcones $(2 \mathrm{a}-2 \mathrm{e})$.

\begin{tabular}{|ccccccc|}
\hline $\begin{array}{c}\text { Conc. } \\
\left(\mathbf{m o l ~ L} \mathbf{~}^{-}\right)\end{array}$ & Blank & $\mathbf{2 a}$ & $\mathbf{2 b}$ & $\mathbf{2 c}$ & $\mathbf{2 d}$ & $\mathbf{2 e}$ \\
\hline $\mathbf{3 . 0 \times 1 \mathbf { 1 0 } ^ { - \mathbf { 7 } }}$ & $26.99 \pm 5.90$ & $30.77 \pm 2.37$ & $33.72 \pm 2.43$ & $30.69 \pm 2.20$ & $27.18 \pm 1.58$ & $3056 \pm 1.97$ \\
\hline $\mathbf{3 . 0} \times \mathbf{1 0}^{-\mathbf{6}}$ & $26.99 \pm 5.90$ & $29.83 \pm 2.76$ & $31.35 \pm 2.08$ & $29.69 \pm 1.61$ & $31.05 \pm 1.44$ & $30.13 \pm 2.81$ \\
\hline $\mathbf{6 . 0} \times \mathbf{1 0}^{-\mathbf{6}}$ & $26.99 \pm 5.90$ & $28.32 \pm 2.44$ & $26.54 \pm 2.03$ & $29.72 \pm 1.98$ & $31.25 \pm 1.63$ & $29.67 \pm 2.73$ \\
\hline $\mathbf{1 . 2 \times 1 0 ^ { - 5 }}$ & $26.99 \pm 5.90$ & $28.27 \pm 2.17$ & $30.29 \pm 2.18$ & $30.41 \pm 2.43$ & $30.00 \pm 2.49$ & $30.21 \pm 2.52$ \\
\hline $\mathbf{2 . 4} \times \mathbf{1 0}^{-5}$ & $26.99 \pm 5.90$ & $28.82 \pm 2.62$ & $28.72 \pm 3.60$ & $30.91 \pm 3.05$ & $30.91 \pm 3.05$ & $29.75 \pm 2.42$ \\
\hline $\mathbf{3 . 0} \times \mathbf{1 0}^{-5}$ & $26.99 \pm 5.90$ & $31.27 \pm 2.65$ & $30.39 \pm 1.64$ & $31.71 \pm 3.44$ & $32.90 \pm 3.37$ & $30.34 \pm 2.03$ \\
\hline
\end{tabular}




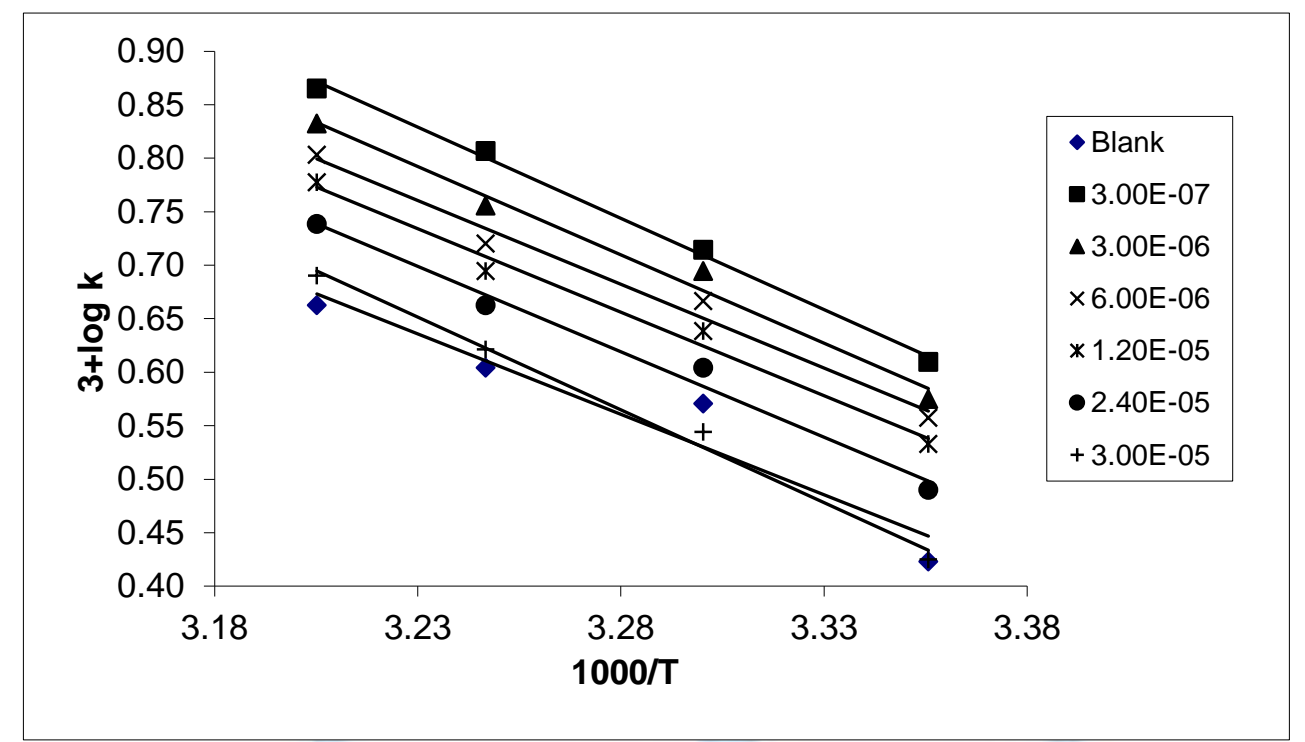

Figure 4. The relation between log $\mathrm{k}$ and 1000/T for $100 \mathrm{ppm} \mathrm{Cr}{ }^{6+}$ solution containing different concentrations of (2a) at $750 \mathrm{rpm}$.

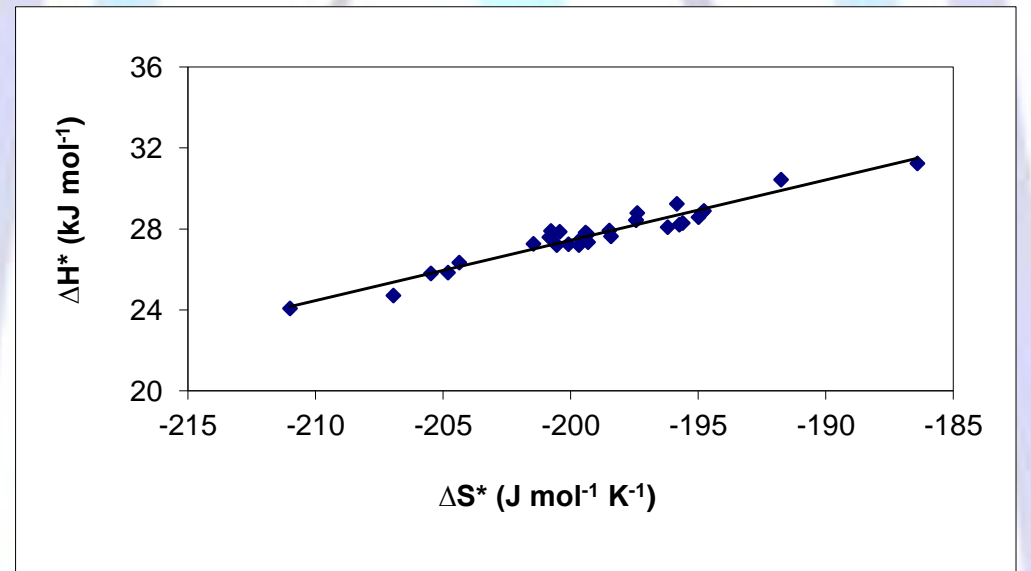

Figure 5. The relation between $\Delta \mathrm{H}^{*}$ and $-\Delta \mathrm{S}^{*}$ for blank solution and in presence of Chalcones $(2 \mathrm{a}-2 \mathrm{e})$ at $25^{\circ} \mathrm{C}$ and 750 rpm.

\subsubsection{Effect of chalcone derivatives on the reduction of $\mathrm{Cr}(\mathrm{VI})$}

In our study, the presence of chalcone increases or accelerates the reaction rate than blank as shown in Table 4. As the concentration of chalcone derivatives increases the reduction rate decreases, this explains as the concentration of chalcones increases the viscosity of solution increases and mass transfer coefficient of $\mathrm{Cr}(\mathrm{VI})$ decrease. So the reaction rate decreases. Also, another factor led to decreases the reaction rate is the steric hinder of chalcones. The percentage acceleration for different concentrations of the studied additives is estimated at $25^{\circ} \mathrm{C}$ as shown in Table 7 . The percentage acceleration is represented by the following equation:

$$
\% \text { Acceleration }=\left(k-k_{0}\right) / k_{0} \times 100
$$

where $k$ and $k_{o}$ are the mass transfer coefficient with and without chalcone respectively. From Table 7 , the order of increasing the \% accelerationis as follows: $2 d>2 c>2 a>2 e>2 b$

\subsection{Quantum chemical parameters of chalcone derivatives}

According to the last classification of accelerator, variation in \% acceleration of chalcone derivatives depend on charge densities of the $\mathrm{O}$-, $\mathrm{N}$-centers and the ability of $\mathrm{Cr}(\mathrm{VI})$ ions to coordinate with them, ${ }^{26}$ Since $\mathrm{Cr}(\mathrm{VI})$ is considered as heavy metal ion so it tends to coordinate with the harder site in the organic additive which is the oxygen molecule. Table 8 shows the order of increasing the -ve charge density of the oxygen atom where, donating groups such as $-\mathrm{CH}_{3}$ increase electron density on oxygen atoms which accordingly increases $\mathrm{Cr}-\mathrm{O}$ bond strength and decreases the reaction rate.In case of electron withdrawing groups such as $\mathrm{Cl}^{-}, \mathrm{Br}^{-}$which decrease the electron density on the oxygen atom which decreasing the bond strength and led to increase the facility of ion diffusion and electron exchange in the reaction medium resulting in increasing the reaction rate. Figure 6 shows the atom numbering scheme and the optimized geometry of the $2 a$. 
Table 6. The thermodynamic parameters for blank solution and solution containing chalcones $(2 \mathrm{a}-2 \mathrm{e})$ at $25^{\circ} \mathrm{C}$ and 750 rpm.

\begin{tabular}{|c|c|c|c|}
\hline Conc. $\mathrm{mol} \mathrm{L}^{-1}$ & $\Delta \mathrm{S}^{*}\left(\mathrm{~J} \mathrm{~mol}^{-1} \mathrm{~K}^{-1}\right)$ & $\Delta \mathrm{H}^{*}\left(\mathrm{~kJ} \mathrm{~mol}^{-1}\right)$ & $\Delta \mathrm{G} *\left(\mathrm{~kJ} \mathrm{~mol}^{-1}\right)$ \\
\hline Blank & $-211.48 \pm 19.28$ & $24.52 \pm 5.87$ & $87.57 \pm 11.64$ \\
\hline \multicolumn{4}{|c|}{$2 \mathrm{a}$} \\
\hline $3.0 \times 10^{-7}$ & $-195.62 \pm 7.78$ & $28.29 \pm 2.38$ & $86.61 \pm 4.70$ \\
\hline $3.0 \times 10^{-6}$ & $-199.33 \pm 9.20$ & $27.351 \pm 2.81$ & $86.791 \pm 5.55$ \\
\hline $6.0 \times 10^{-6}$ & $-204.81 \pm 7.98$ & $25.84 \pm 2.46$ & $86.91 \pm 2.82$ \\
\hline $1.2 \times 10^{-5}$ & $-205.48 \pm 7.11$ & $25.79 \pm 2.17$ & $87.06 \pm 4.29$ \\
\hline $2.4 \times 10^{-5}$ & $-204.37 \pm 8.59$ & $26.34 \pm 2.62$ & $87.28 \pm 5.18$ \\
\hline $3.0 \times 10^{-5}$ & $-197.39 \pm 8.69$ & $28.79 \pm 2.65$ & $87.64 \pm 5.24$ \\
\hline \multicolumn{4}{|c|}{$2 b$} \\
\hline $3.0 \times 10^{-7}$ & $-186.41 \pm 7.96$ & $31.24 \pm 2.38$ & $86.82 \pm 4.80$ \\
\hline $3.0 \times 10^{-6}$ & $-194.78 \pm 6.81$ & $28.89 \pm 2.08$ & $86.97 \pm 2.08$ \\
\hline $6.0 \times 10^{-6}$ & $-211.00 \pm 6.66$ & $24.06 \pm 2.03$ & $86.97 \pm 4.01$ \\
\hline $1.2 \times 10^{-5}$ & $-199.42 \pm 7.15$ & $27.82 \pm 2.18$ & $87.26 \pm 4.31$ \\
\hline $2.4 \times 10^{-5}$ & -200.8512 .09 & $27.59 \pm 3.69$ & $87.48 \pm 7.23$ \\
\hline $3.0 \times 10^{-5}$ & $-200.78 \pm 5.19$ & $27.91 \pm 1.64$ & $87.76 \pm 3.24$ \\
\hline \multicolumn{4}{|c|}{$2 \mathrm{c}$} \\
\hline $3.0 \times 10^{-7}$ & $-195.75 \pm 7.22$ & $28.21 \pm 2.20$ & $86.58 \pm 4.35$ \\
\hline $3.0 \times 10^{-6}$ & $-199.69 \pm 5.28$ & $27.21 \pm 1.61$ & $86.75 \pm 3.19$ \\
\hline $6.0 \times 10^{-6}$ & $-200.09 \pm 6.50$ & $27.25 \pm 1.98$ & $86.90 \pm 3.91$ \\
\hline $1.2 \times 10^{-5}$ & $-198.49 \pm 7.95$ & $27.92 \pm 2.42$ & $87.11 \pm 4.79$ \\
\hline $2.4 \times 10^{-5}$ & $-197.44 \pm 10.00$ & $28.43 \pm 3.05$ & $87.28 \pm 6.04$ \\
\hline $3.0 \times 10^{-5}$ & $-195.85 \pm 11.26$ & $29.23 \pm 3.44$ & $87.62 \pm 6.80$ \\
\hline \multicolumn{4}{|c|}{$2 \mathrm{~d}$} \\
\hline $3.0 \times 10^{-7}$ & $-206.96 \pm 5.17$ & $24.70 \pm 1.58$ & $86.40 \pm 3.12$ \\
\hline $3.0 \times 10^{-6}$ & $-195.00 \pm 4.71$ & $28.57 \pm 1.44$ & $86.71 \pm 2.84$ \\
\hline $6.0 \times 10^{-6}$ & $-194.87 \pm 5.34$ & $28.78 \pm 1.63$ & $86.88 \pm 3.23$ \\
\hline $1.2 \times 10^{-5}$ & $-199.58 \pm 8.17$ & $27.52 \pm 2.50$ & $87.02 \pm 4.93$ \\
\hline $2.4 \times 10^{-5}$ & $-197.44 \pm 10.02$ & $28.43 \pm 3.05$ & $87.29 \pm 6.03$ \\
\hline $3.0 \times 10^{-5}$ & $-191.76 \pm 10.86$ & $30.43 \pm 3.37$ & $87.60 \pm 6.67$ \\
\hline \multicolumn{4}{|c|}{$2 \mathrm{e}$} \\
\hline $3.0 \times 10^{-7}$ & $-196.20 \pm 6.54$ & $28.09 \pm 1.97$ & $86.63 \pm 3.89$ \\
\hline $3.0 \times 10^{-6}$ & $-198.43 \pm 9.20$ & $27.64 \pm 2.81$ & $86.80 \pm 5.55$ \\
\hline $6.0 \times 10^{-6}$ & $-200.55 \pm 8.92$ & $27.20 \pm 2.73$ & $86.99 \pm 5.39$ \\
\hline $1.2 \times 10^{-5}$ & $-199.34 \pm 8.23$ & $27.73 \pm 2.52$ & $87.17 \pm 4.97$ \\
\hline $2.4 \times 10^{-5}$ & $-201.47 \pm 7.93$ & $27.27 \pm 2.42$ & $87.34 \pm 4.88$ \\
\hline $3.0 \times 10^{-5}$ & $-200.44 \pm 6.65$ & $27.86 \pm 2.03$ & $87.63 \pm 4.01$ \\
\hline
\end{tabular}


Table 7.The relation between $\%$ acceleration and concentration of chalcones (2a-2e) at $25^{\circ} \mathrm{C}$ and $750 \mathrm{rpm}$.

\begin{tabular}{|c|c|c|c|c|c|c|}
\hline \multirow{2}{*}{$\mathrm{T}\left({ }^{\circ} \mathrm{C}\right)$} & Conc. & \multicolumn{5}{|c|}{ \% Acceleration } \\
\cline { 3 - 7 } & $\mathrm{mol} \mathrm{L}^{-1}$ & $2 \mathrm{a}$ & $2 \mathrm{~b}$ & $2 \mathrm{c}$ & $2 \mathrm{~d}$ & $2 \mathrm{e}$ \\
\hline \multirow{5}{*}{25} & $3.0 \times 10^{-7}$ & 53.58 & 40.75 & 56.60 & 69.43 & 52.83 \\
\cline { 2 - 7 } & $3.0 \times 10^{-6}$ & 41.89 & 33.21 & 46.04 & 48.30 & 40.75 \\
\cline { 2 - 7 } & $6.0 \times 10^{-6}$ & 36.23 & 26.79 & 36.98 & 38.11 & 30.57 \\
\cline { 2 - 7 } & $1.2 \times 10^{-5}$ & 28.68 & 18.87 & 25.28 & 29.43 & 22.64 \\
\cline { 2 - 7 } & $2.4 \times 10^{-5}$ & 16.60 & 12.83 & 15.09 & 18.87 & 13.96 \\
\cline { 2 - 7 } & $3.0 \times 10^{-5}$ & 0.38 & 0.00 & 0.38 & 2.26 & 1.89 \\
\hline
\end{tabular}

Table 8.The calculated charge densities on all heteroatom of the organic additives used.

\begin{tabular}{|c|c|c|c|c|c|c|}
\hline \multicolumn{2}{|c|}{} & N1 & N2 & N3 & N4 & O1 \\
\hline \multirow{2}{*}{ a } & AM1 & -0.04635 & -0.104061 & 0.028935 & -0.109514 & -0.281517 \\
\cline { 2 - 7 } & PM3 & 0.061438 & -0.027866 & -0.128718 & 0.269416 & -0.297417 \\
\hline \multirow{2}{*}{ b } & AM1 & -0.046359 & -0.104310 & 0.028960 & -0.109662 & -0.283360 \\
\cline { 2 - 7 } & PM3 & 0.061425 & -0.028148 & -0.128431 & 0.269018 & -0.298705 \\
\hline \multirow{2}{*}{ c } & AM1 & -0.046324 & -0.103140 & 0.028704 & -0.109012 & -0.277795 \\
\cline { 2 - 7 } & PM3 & 0.059174 & -0.024560 & -0.124427 & 0.266890 & -0.295962 \\
\hline \multirow{2}{*}{ d } & AM1 & -0.046317 & -0.102967 & 0.028777 & -0.108926 & -0.275432 \\
\cline { 2 - 7 } & PM3 & 0.059296 & -0.024212 & -0.125191 & 0.267755 & -0.293749 \\
\hline \multirow{2}{*}{ e } & AM1 & -0.046372 & -0.104059 & 0.029078 & -0.109552 & -0.281402 \\
\cline { 2 - 7 } & PM3 & 0.061493 & -0.027741 & -0.128977 & 0.269164 & -0.297194 \\
\hline
\end{tabular}

Table 9.The calculated quantum chemical parameters for the investigated inhibitors.

\begin{tabular}{|ccccccc|}
\hline & $E_{\text {HOMO }}$ & $\mathrm{E}_{\text {LUMO }}$ & $\Delta \mathrm{E}$ & $\mu$ & $\eta$ & $\sigma$ \\
\cline { 2 - 7 } Molecule & $(\mathrm{eV})$ & $(\mathrm{eV})$ & $(\mathrm{eV})$ & $(\mathrm{D})$ & $(\mathrm{eV})$ & $\left(\mathrm{eV}^{-1}\right)$ \\
\hline $2 \mathrm{a}$ & -8.113 & 0.554 & 8.667 & 0.882 & 4.333 & 0.2307 \\
\hline $2 \mathrm{~b}$ & -7.973 & 0.683 & 8.656 & 0.900 & 4.328 & 0.2311 \\
\hline $2 \mathrm{c}$ & -8.134 & 0.536 & 8.669 & 1.044 & 4.335 & 0.2306 \\
\hline $2 \mathrm{~d}$ & -7.985 & 0.705 & 8.689 & 1.100 & 4.345 & 0.2302 \\
\hline $2 \mathrm{e}$ & -8.004 & 0.655 & 8.659 & 0.885 & 4.329 & 0.2309 \\
\hline
\end{tabular}

The HOMO-LUMO energy gap, $\Delta \mathrm{E}$ approach, which is an important stability index, is applied to develop theoretical models for explaining the structure and conformation barriers in many molecular systems. The greater is the value of $\Delta \mathrm{E}$, the more is the probable acceleration efficiency that the compound has. It was shown from Table 9that $2 \mathrm{~d}$ molecule has the greatest HOMO-LUMO gap $(8.68975 \mathrm{eV})$ compared with the other derivatives. Accordingly, it could be expected that $2 \mathrm{~d}$ molecule has more inclination to increase the rate of reduction in the metal surface than the other molecules. The dipole moment values in Table 8 indicate that the \% acceleration rates are directly proportional to the polarity of the chalcone derivatives. Absolute hardness, $\eta$ and softness, $\sigma$ are important properties to measure the molecular stability and reactivity. A hard molecule has a large energy gap and a soft molecule has a small energy gap. Accordingly, it is concluded that $2 \mathrm{~d}$ accelerator with the lowest $\sigma$ value has the highest acceleration efficiency (Table 9 ) which is in a good agreement with the experimental data. ${ }^{27}$ 


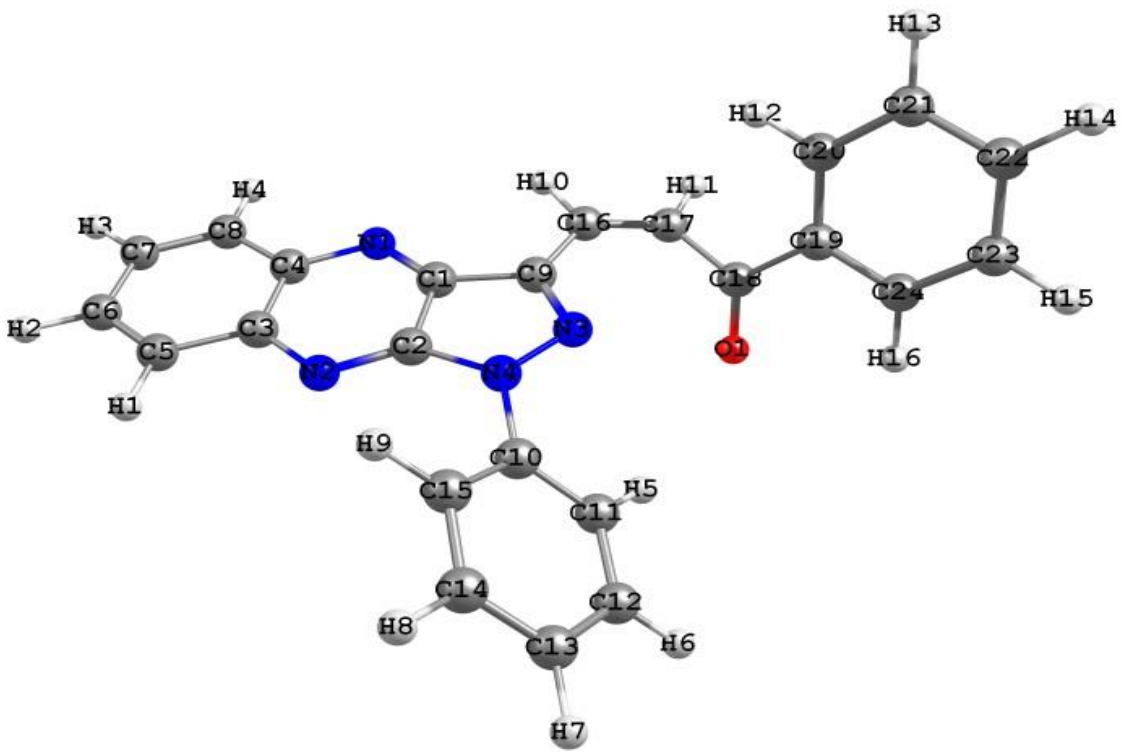

Figure 6.The atom numbering scheme and the optimized molecular geometry of 2a using PM3.

\subsection{Data correlation}

Applying the method of dimensional analysis, we can be written as:

$$
S h=a S c^{b} R e^{c}
$$

where the Sherwood number $(S h=k d / D)$, Schmidt number $(S c=v / D)$ where $v$ is kinematics viscosity and Reynolds number $(R e=V d / v)$, $a$ and $c$ are empirical constants and the exponent of the Schmidt number in the general mass transfer correlation was fixed at an established value of $0.33 .{ }^{28}$

By plotting logSh/ $\mathrm{Sc}^{0.33}$ against log Re gives a straight line, where their slopes give the constant $c$ and intercept gives the constant $a$. The data can be correlated by the following equations:

$$
\begin{array}{ll}
\text { Sh }=0.53 \mathrm{Sc}^{0.33} \mathrm{Re}^{0.38} & \text { for } 2 \mathrm{a} \\
\mathrm{Sh}=0.44 \mathrm{Sc}^{0.33} \mathrm{Re}^{0.40} & \text { for } 2 \mathrm{~b} \\
\mathrm{Sh}=0.57 \mathrm{Sc}^{0.33} \mathrm{Re}^{0.37} & \text { for } 2 \mathrm{c} \\
\mathrm{Sh}=0.64 \mathrm{Sc}^{0.33} \mathrm{Re}^{0.35} & \text { for } 2 \mathrm{~d} \\
\mathrm{Sh}=0.48 \mathrm{Sc}^{0.33} \mathrm{Re}^{0.39} & \text { for } 2 \mathrm{e}
\end{array}
$$

Figure 7 gives the overall correlation for all chalcones which correlated by the equation:Sh $=0.53 \mathrm{Sc}^{0.33} \mathrm{Re}^{0.38}$. The present Re exponent $(0.4$ is in good agreement with a diffusion-controlled reaction under the turbulent mass transfer mechanism in the presence of pyrazoloquinoxaline derivative molecules. $1,21,28$

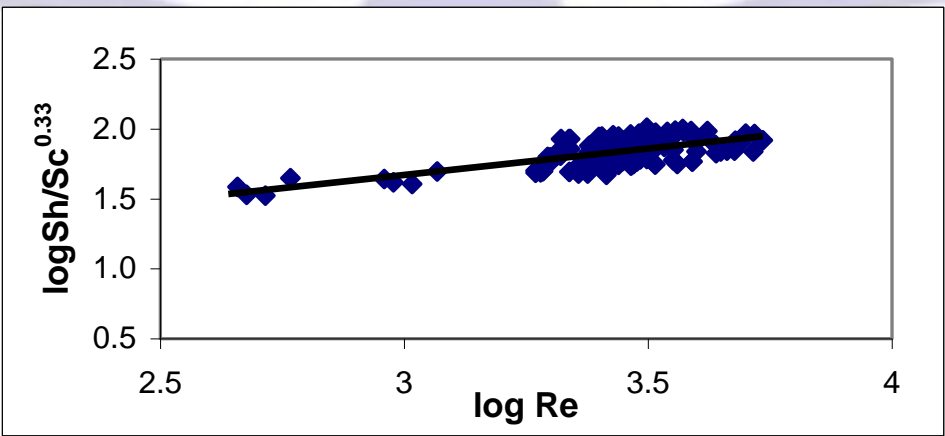

Figure 7.The overall mass transfer relation for the $\mathrm{Cr}(\mathrm{VI})$ solution in the presence of all chalcones.

\section{CONCLUSION}

In this work, we have investigated the effect of pyrazoloquinoxaline derivatives, which attached to chalcone moiety as a side chain on the rate of reduction of $\mathrm{Cr}(\mathrm{VI})$ to $\mathrm{Cr}$ (III) on iron sheet.Rate of reaction increases by increasing the 
concentration, decreasing viscosity, increasing diffusion coefficient and increasing temperature. The oxidation - reduction reaction is found to be first order reaction and the controlling step is the diffusion of $\mathrm{Cr}(\mathrm{VI})$ from bulk to iron surface.The \% acceleration caused by pyrazoloquinazoline depending on the case of substituting group attached to heterocyclic moiety and its concentration. The rate of the reaction increases by increasing the rotation speed which supports that reaction diffusion controlled reaction. The values of the activation energy below $42 \mathrm{~kJ} \mathrm{~mol}^{-1}$ which indicate that the reaction was diffusion controlled reaction.Isokinetic temperature represents the variation of $\Delta \mathrm{H}^{*}$ with $\Delta \mathrm{S}^{*}$ for all organic compounds used to designate a close similarity in the mechanism. The present $\mathrm{Re}$ exponent $\approx 0.4$ is in good agreement with a diffusion-controlled reaction under turbulent flow.All studied quantum chemical parameters confirm the order of acceleration which agrees with experimental results.

\section{REFERNCES}

[1] Trebien, D. O. P.;Bortolon, L.; Tedesco, M. J.; Bissani, C. A.; Camargo, F. A. O. 2011. Pedosphere21.84.

[2] Bozzini, B.; Amati, M.;Abyaneh, M. K.;Gregoratti, L.; Kiskinova, M. 2011.J. Electroanal. Chem.657. 113.

[3] Gardea-Torresdey, J. L.;Tiemann, K. J.; Armendariz, V.; Bess-Oberto, L.;Chianelli, R. R.; Rios, J.; Parsons, J. G.; Gamez, G. 2000. J. Hazard. Mater.80.175.

[4] Kowalski, Z. 1994.J. Hazard. Mater.37. 137.

[5] Satin, V.; Pant, K. K. 2006.Bioresource Technol. 97. 15.

[6] USEPA 1980 Ambient Water quality Criteria for Chromium.1980.EPA 440/5-80-035 p. PC31.

[7] Rojas, G.; Silva, J.; Flores, J. A.; Rodriguez, A.; Ly, M.; Maldonado, H. 2005.Separation Purif. Technol. 44. 31.

[8] Lee, T.; Lim, H.; Lee, Y.; Wpark, J. 2003. Chemoshere. 53. 479.

[9] Ponder, M.;Darab, J. G.; Mallouk, T. E.2000. Environ. Sci. Technol. 34. 2564.

[10] Alowitz, M. J.; Scherer, M. M. 2002. Environ. Sci. Technol. 36. 299.

[11] Tomar, V.;Bhattacharjee, G. K.; Kumar, A. 2007. Biorg. Med. Chem. Lett. 17. 5321.

[12] Abdel Zaher, M.2005.Alex. J. Pharm. Sci. 19. 63.

[13] Sastri, V. S.; Perumareddi, J. R.1996. Corrosion. 53. 671.

[14] Perason, R. G.1988. Inorg. Chem.27. 734.

[15] Guerra, E.; Dreisinger, D. B.1999. Hydrometallurgy.51. 155.

[16] Zarra, M. A.1996. Hydrometallurgy. 41. 231.

[17] Makhloufi, L.;Saidani, B.; Hammache, H.2000. Wat. Res. 34. 2517.

[18] Gasser, M. S.;Morad, G. H. A.; Aly, H. F.2007. J. Hazard. Mater. 142. 118.

[19] Dönmez, B.;Sevim, F.; Saraç, H. 1999. Hydrometallurgy. 53. 145.

[20] Deb, A.; Makhloufi, L.2006. Chem. Eng. J. 130. 39.

[21] Singh, D. B.;Rupainwar, D. C.; Prasad, G. J.1992. J. Chem. Technol. Biotechnol.53. 127.

[22] Makhloufi, L.;Bourouina, S.; Haddad, S. 1992.Electrochim. Acta. 34. 1779.

[23] El-Subruiti, G. M. 2002J. Solution Chem.31. 415.

[24] Demirkiran, N.;Ekmekyapar, A.;Kunkul, A.; Baysar, A. 2007.Int. J. Miner. Process. 82. 80.

[25] Hao, J.;Poë, A. J.1997. Transition Met. Chem. 23. 739.

[26] Abdel Rahman, H. H.; Abdel Wahed, E. M.2012. Hydrometallurgy. 129-130. 111.

[27] Awad, M. K.; Mustafa, M. R.; Abo Elnga, M. M. 2010.J. Mol. Struct. (THEOCHEM). 959. 66.

[28] Soltan, E. A.; Nosier, S. A.; Salem, A. Y.; Mansour, G. H. 2002. J. Chem. Eng. 91. 33. 